\title{
Reformasi Menuju Hukum Progresif
}

\author{
Satjipto Rahardjo
}

As has been generally known, Indonesian legal system nowadays suffers with a lot of weaknesses. Some people are on opinion that this is as a form of degradation of the quality of law in this country. To Overcome this situation, some effort to reconstruct paradigm of legal system is absolutely needed. The aimed effort is also called as a Progressive Law. In order to optimize this effort, the enlighment of all legal embodied components such as education, legislation, court and legal enforcement must be made. One of key factors to create Progressive Law is human resources. Therefore, reorientation on curriculum and also teaching system on legal studies is so important in this context.

\begin{abstract}
Q ebaiknya pikiran untuk merekonstruksi hukum Indonesia sekarang ini dimulai dari rekonstruksi pemikiran hukum, sehingga rekonstruksi hukum sudah menjadi identik dengan rekonstruksi pemikiran hukum. Gagasan ini baik untuk dicoba, oleh karena selama ini rekonstruksi hukum selalu dikaitkan pada masalah perundangundangan, institusi dan para pelaku. Sampai hari ini cara yang demikian belum bisa memberikan hasil yang memuaskan, bahkan kualitas hukum banyak mengalami kemunduran .
\end{abstract}

Rekonstruksi pemikiran hukum disini ingin ditempatkan pada suatu platform tertentu, yaitu Hukum Progresif (HPr). Dengan platform pemikiran yang demikian itu diharapkan, bahwa gagasan HPr akan memberikan pencerahan dan penjiwaan terhadap sekian komponen sistem hukum, seperti pendidikan, legislasi, peradilan dan penegakan hukum.

\section{Manusia menjadi Titik Pusat}

Pada aras yang amat dasar dari $\mathrm{HPr}$ adalah filsafat tentang hubungan antara hukum manusia. Manusia menjadi titik pusat, sedang apa yang dilakukan oleh hukum sangat tergantung pada manusia. Dirumuskan secara bernas, maka "Hukum adalah untuk Manusia". Kalau dikenal perumpamaan "Het recht hinkt achter de feiten" (hukum berjalan tertatih-tatih di belakang kenyataan), maka di sini kalimat tersebut menjadi "Het recht hinkt achter de mens" (hukum berjalan tertatih-tatih dibelakang manusia).

Dalam HPr, manusia menempati kedudukan pusat. Hukum tidak memiliki kedudukan absolut, melainkan selalu dikaitkan pada manusia. Puncaknya adalah, bahwa hukum diadakan untuk membawa kebahagiaan kepada manusia. Filsafat yang demikian itu lebih lagi dirasakan kebutuhan kehadirannya, sejak dihadapkan pada hukum modern. Hukum modern inilah yang sehari-hari dibuat dan dijalankan. 
Hukum modern baru hadir di dunia sekitar abad ke-delapanbelas seiring dengan kelahiran negara modern. Kemunculan hukum modern tersebut mengubah secara dramatis hukum sebelumnya. Sejak saat itu hukum dibuat secara khusus dan dijalankan oleh rejim administrasi yang khusus pula. Kalau selama ribuan tahun sebelumnya hukum itu tidak pernah bisa dipastikan secara positif, maka sejak era hukum modern, hukum itu bisa dikenali dalam bentuknya yang positif, khususnya sebagai dokumen tertulis yang pembuatannya dimonopoli oleh badan legislațif negara.

Perubahan dramatis terjadi, oleh karena dalam urusan hukum kita tidak lagi hanya berbicara tentang keadilan dan kebenaran, melainkan tentang peraturan atau perundang-undangan. Maka terjadilah pergeseran besar, saat hukum itu tidak lagi bisa diandalkan sebagai institusi keadilan, melainkan juga menjadi institusi tempat peraturan dijalankan. Sejak saat itu menjalankan atau menegakkan peraturan menjadi salah satu tiang yang kokoh dalam peradaban hukum modern. Pengadilan berubah menjadi institusi publik yang sarat dengan birokrasi, prosedur-prosedur, formalitas dan sebagainya. Untuk bisa berhasil dalam urusan hukum orang harus ahli menguasai peraturan hukum dan pandai-pandai mempermainkan prosedur. Itulah tragedi hukum modern. Mulai saat itu menjalankan peraturan hampir sinonim dengan menegakkan hukum. Aspek keadilan dan kebenaran mengalami marjinalisasi yang besar. Pengadilan tidak lagi menjadi tempat untuk mendapatkan keadilan, melainkan untuk mencari kemenangan, sehingga muncullah fenomena "trials without truth"(Pizzi, 1999). Pizzi menunjuk kepada peran Hakim yang pasif sehingga fenomena ini bisa terjadi. "They permit and axpect judges to play an active role at trial in order to help see that justice is done".

Berdasarkan uraian di atas, maka untuk membalikkan keadaan, sehingga hukum itu benar-benar membawa kesejahteraan dan kebahagiaan kepada manusia, kita perlu menegaskan dengan kuat, bahwa hukum itu adalah untuk manusia dan bukan untuk sebaliknya. Oleh karena itu kita tidak boleh menjadi tawanan dari peraturan. Tidak hanya peraturan, tetapi juga asas, doktrin, juga perlu dilihat dalam konteks pemahaman tersebut. Bukan manusia untuk asas dan doktrin hukum, tetapi asas hukum itulah yang untuk manusia.

Mengikuti logika yang didasarkan pada keyakinan mendasar tersebut, maka bilamana diperlukan keberanian untuk melakukan pembebasan-pembebasan dari tradisi dan konvensi. Pembebasan merupakan bagian penting dari alam pikiran $\mathrm{HPr}$. Kita tidak perlu ragu-ragu mengenai langkah itu, oleh karena dalam sejarah dijumpai bangsa-bangsa yang pernah melakukan pembebasan seperti itu. Amerika Serikat melakukan hal itu, pada waktu meminggirkan doktrin Trias Politica yang dianggap menghambat pembangunan Amerika modern pada masa itu. Di abad ke-sembilanbelas mereka dengan menantang reaksi dunia dengan mengatakan, bahwa itu adalah "the distinctively American development", the American concept of law", "American doctrines". Dicontohkan oleh Gilmore, bagaimana pengadilan Amerika menyimpang dan membebaskan diri doktrin dan konvensi yang ada pada waktu itu. "A feature of the American approach to law which has always bewildered and infrequently shocked foreign observers is that our courts routinely assumed jurisdiction over issues which in most other countries are thought to lie well beyond the limits of judicial com- 
petence". Langkah atau tindakan seperti itu memancing sebutan "government by judiciary" (Schwartz, 1993). Sehubungan dengan langkah kontroversial tersebut, Hakim Agung Cardozo memberi alasan, " $A$ gospel of laissez-faire... may be inadequate in the great society that we live in to point the way to salvation, at least for economic life. The conception of the proper role of government upon which the 1934-1936 decisions were based was utterly inconsistent with an era which demanded ever-expanding governmental authority".

HPr berbagi pendapat yang sama dengan keberanian untuk melakukan pembebasan sebagaimana dilakukan oleh pengadilan di Amerika Serikat di masa itu. HPr juga menginginkan agar pengadilanpengadilan kita, khususnya Mahkamah Agung tidak segan dan ragu untuk melakukan pembebasan apabila negara dan bangsa membutuhkan.

\section{Pendidikan sebagai Kunci}

Pendidikan niscaya menempati kedudukan yang sangat sentral dan strategis bagi penyebaran dan penyemaian gagasan $\mathrm{HPr}$, khususnya sebagai tempat penjabaran intelektual konsep dasar "hukum adalah untuk manusia". Kurikulum ditinjau kembali, demikian pula dengan sistem penyampaiannya (delivery system). Perhatian seksama akan diberikan kepada materi mata kuliah filsafat hukum dan pilihan teori-teori hukum yang disampaikan kepada para mahasiswa. Penilaian dan peninjauan kembali dicerahkan oleh filsafat hubungan antara manusia dan hukum tersebut di atas.

HPr membutuhkan dukungan teori dan aliran, sepertiAliran Realisme Hukum serta Teori Hukum Responsif dari Nonet dan Selznick (Nonet \& Selznick, 1978). Keduaduanya berwatak pembebasan terhadap pemikiran hukum yang ada. Realisme membebaskan diri dari positivisme dan analitical jurisprudence, sedang Hukum Responsif membebaskan dari konsep Hukum Otonom.

$\mathrm{HPr}$ juga berkepentingan agar para mahasiswa tidak hanya membaca dan mempelajari teks dan menggunakan logika peraturan, melainkan didorong untuk mendalami makna hukum (baca: peraturan). Hukum tidak ada untuk dirinya sendiri, melainkan untuk manusia dan masyarakat. Oleh karena itu setiap peraturan, baik yang subtantif maupun prosedural, hendaknya dibaca dengan kacamata maknanya untuk manusia dan sosial.

HPr lebih mengutamakan manusia di atas hukum. Oleh karena itu maka di samping pembelajaran mengenai teks-teks peraturan, menjadi penting wacana mengenai perilaku manusia dalam hukum. Hukum adalah teks-teks yang diam dan mati dan hanya ditangan manusialah hukum menjadi hidup. Oleh karena itu suntikan keberanian kepada para penegak hukum diharapkan akan membawa kebangunan hukum Indonesia.

\section{Penutup}

Untuk mengatasi keterpurukan hukum Indonesia tidak ada jalan lain kecuali melakukan mobilisasi hukum menuju kehidupan bangsa yang lebih baik. Amerika Serikat sudah memberikan contoh yang bagus yang dengan berani mengatakan, "inilah konsep Amerika tentang hukum". Sekarang kita juga ingin mengatakan, "Inilah konsep Indonesia mengenai hukum". Mobilisasi hukum ini dilakukan oleh siapa saja, Hakim, Jaksa, Polisi, Advokat, akademisi dan teoritisi, legislator dan birokrasi pemerintahan. Mobilisasi hukum juga dijalankan di mana saja, pada lapisan 
yang mana saja, tidak hanya di tingkat nasional melainkan juga lokal. Mobilisasi hukum tidak hanya dilakukan oleh hakimhakim nasional, tetapi juga hakim, jaksa, polisi dan advokat kecil di daerah-daerah.

\section{Daftar Pustaka}

Gilmore, Grant, 1977, The Ages of American Law, New Haven: Yale University Press.

Nenet, Philippe \& Philip Selznick, 1978, Law and Society in Transistion: Toward
Responsive Law, New York : Harper \& Row.

Pizzi, William T., 1999, Trials Without Truth, New York: New York University Press.

Schwartz, Bernard, 1993, A History of the Supreme Court, New York: Oxford University Press. 